
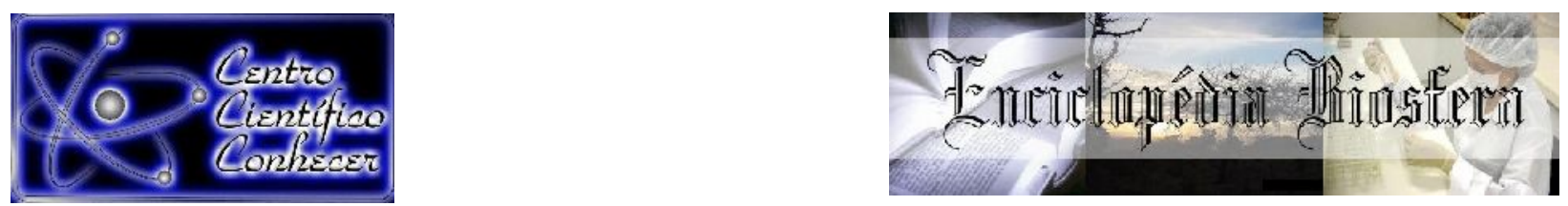

\title{
A SUSTENTABILIDADE PENSADA E CONSTRUÍDA A PARTIR DE UMA ONG: UM ESTUDO SOBRE PROJETOS E AÇÕES EDUCATIVAS DO INSTITUTO CURUPIRA (ICASA)
}

\author{
Delton Mendes Francelino ${ }^{1 *}$ e Vitória Cássia Gabriela de Oliveira ${ }^{2 *}$ \\ ${ }^{1}$ Coordenador do Centro de Estudos em Ecologia Urbana - Instituto Federal de \\ Educação Ciência e Tecnologia do Sudeste de Minas Gerais - Campus Barbacena \\ ${ }^{2}$ Licenciada em Ciências Biológicas - membro do Centro de Estudos em Ecologia \\ Urbana - Instituto Federal de Educação Ciência e Tecnologia do Sudeste de Minas \\ Gerais - Campus Barbacena \\ E-mail: vitoriaoliveirabio@gmail.com
}

\section{Recebido em: 15/05/2020 - Aprovado em: 15/06/2020 - Publicado em: 30/06/2020 DOI: 10.18677/EnciBio_2020B3}

\begin{abstract}
RESUMO
A realidade mundial de extrema degradação da natureza, apropriação inconsequente de recursos naturais, além de conflitos sociais e ambientais diversos, tem exigido novas metodologias e processos de sensibilização ambiental que sejam capazes de gerar e estimular novos modelos de atuação humana no globo. ONG's (Organizações Não Governamentais) têm despontado como importantes espaços de construção de novas culturas de sustentabilidade, oferecendo base para a elaboração, inclusive, de políticas públicas e projetos pedagógicos críticos interessantes. O Instituto Curupira (ICASA), Brasil, tem despontado como uma dessas instituições, com importantes e significativos projetos baseados na educação alternativa, objetivando a construção de valores e sentidos ambientais múltiplos em diversas instâncias da sociedade. Este artigo busca compreender melhor o ICASA por meio de alguns de seus projetos, ações e documentos, compreendendo essas iniciativas como modelos de fomento de espaços de resistência capazes de fortalecer a perspectiva de um futuro sustentável. Metodologicamente, recorreu-se a autores, e quadros reflexivos, que discutem análise de conteúdo, racionalidade ambiental, educação e sustentabilidade.
\end{abstract}

PALAVRAS-CHAVE: ONG, processos educativos,sustentabilidade

\section{SUSTAINABILITY BUILT THROUGH TRANSDISCIPLINARY PROCESSES: A STUDY ON CURUPIRA INSTITUTE'S EDUCATIVE PROJECTS AND ACTIONS}

\begin{abstract}
The global reality of extreme degradation of nature, inconsequent appropriation of natural resources, in addition to diverse social and environmental conflicts, has called for new methodologies and processes of environmental awareness that are capable of generating and stimulating new models of human action in the globe.Nongovernmental organizations(NGOs) have emerged as important spaces for building new cultures of sustainability, offering basis for the elaboration of public policies and
\end{abstract}

\footnotetext{
** Todos os autores contribuíram de forma igual para o estudo e para a elaboração do artigo. ENCICLOPÉDIA BIOSFERA, Centro Científico Conhecer - Goiânia, v.17 n.32; p. 292020
} 
critical pedagogical projects. The Curupita Institute (ICASA), Brazil, has emerged as one of these institutions, with important and significant projects based on alternative education, aiming at the construction of multiple environmental values and senses in various instances of Society. This article seeks to better understand ICASA, through some of its projects, actions and documents, understanding these initiatives as an incentive of resistance spaces capable of strengthening the prospect of a sustainable future. Methodologically, authors and reflective frameworks were used, which discuss content analysis, environmental rationality, future education and sustainability.

KEYWORDS: educational processes, NGOs, sustainability

\section{INTRODUÇÃO}

Os conflitos ambientais e ecossistêmicos contemporâneos têm mostrado um elevado grau de complexidade e exigido novas metodologias de construção de saberes pela humanidade (MORIN, 2007), muitos erigidos fora dos ambientes acadêmicos e científicos. Esses conflitos, percebidos em sua essência geratriz, são decorrentes de processos complicados e por vezes indefiníveis, sem dúvida calcados em aspectos relacionais que distanciaram a humanidade dos princípios ecológicos (OLIVEIRA et al., 2016). Padrões nefastos de apropriação de recursos naturais, modelados pela estrutura capitalista de compreensão do mundo e do próprio homem (DELLA FONTE, 2019).

Nesse contexto, crescem as discussões sobre como a sustentabilidade pode, de fato, ser buscada e construída, não somente por meio da mera subdivisão dos fatores ambientais, econômicos e sociais, mas, sobretudo, pela associação (ONU, 2015). A transdisciplinaridade e a educação alternativa (ou a educação alternativa baseada em processos transdisciplinares) despontam como elementos fundamentais para a prática de possibilidades de construção de reais perspectivas de mudança cultural do perfil humano de existência nos mais diversos ambientes (GADOTTI, 2016). Nesse igual contexto, tornam-se tão relevantes estudos que observem as práticas educativas e ONGs, entidades muito presentes no Brasil segundo o IBGE (2017) e que podem ser capazes de trazer perspectivas diferentes para uma educação ainda muito tradicionalista no Brasil (ANTUNES et al., 2018).

A interpretação e representação do mundo pela humanidade são organizadas sistemicamente pela cultura (BROCCHI, 2008) e, justamente nesse sentido, esse artigo propõe refletir sobre como a inserção de modelos de educação alternativa/ambiental pelo Instituto Curupira (ICASA), Brasil, e se suas práticas e projetos transdisciplinares, podem representar espaços de esperança para a elaboração e inovação de novos valores e sentidos ambientais na busca pela sustentabilidade, como prevê a própria ONU (2015), na Agenda 2030.

O Instituto Curupira (ICASA) é uma ONG criada em 2012, em Barbacena-MG (Brasil), em formato de escola alternativa, tendo atualmente três núcleos: Barbacena/MG, Campinas/SP e Massachussets/EUA. Suas ações têm repercutido por seus modelos educativos alternativos construídos por processos artísticos, valorização e produção cultural, pesquisas científicas ecológicas e ambientais, cursos de popularização da ciência e variados projetos de educação ambiental crítica e holística (CURUPIRA, 2017). Por esta razão, compreender melhor como suas ações contribuem para a discussão acerca da sustentabilidade ambiental (CAPRA, 2005), foi o foco principal deste estudo. 


\section{MATERIAIS E MÉTODOS}

Metodologicamente, a pesquisa se baseou, a priori, no modelo de análise de conteúdo proposto por Bardin (2010), no qual buscou-se, primeiramente, coletar dados, informações, documentos, para depois partir para a análise e interpretação dos mesmos. Em razão do enfrentamento da pandemia da COVID 19, não houve interação com pessoas da ONG. Assim, três etapas distintas foram definidas: (1) acesso a fontes via internet de informações da ONG, sobretudo seu site oficial, mas também nos perfis em mídias como o Instagram e Facebook, a fim de entender melhor as ações e projetos da entidade. A fim de facilitar as análises, todos os dados e informações coletados com relação a esses projetos, estão disponibilizados no quadro 1 e quadro 2, disponível a posteriori.(2) Na etapa seguinte, buscou-se por materiais de jornais, portais, que pudessem mostrar como a sociedade compreende e é impactada pelas ações do Instituto Curupira; (3) por fim, a partir de todos esses materiais, partiu-se para a interpretação e reflexão dos dados, com embasamento também em teóricos das questões ambientais, sustentabilidade e educação. Para tanto, utilizou-se como aporte teórico elementar, as contribuições de autores como Brocchi (2008), que oferece a perspectiva de que a sustentabilidade está diretamente associada a fatores culturais; Kohan (2019), Antunes et al. (2019), Capra (2005) dentre outros, colaborando com questões educativas; e D'ambrósio (2011) que discute amplamente os elementos que caracterizam um processo transdisciplinar.

\section{Contextualizando a ONG}

\section{RESULTADOS E DISCUSSÃo}

Antes de compreender melhor os projetos e ações educacionais do Instituto Curupira, foi preciso buscar informações sobre a estrutura básica de funcionamento da instituição. A partir dos dados coletados no site oficial da ONG, o quadro 1 abaixo foi elaborado, sintetizando dados que favorecem entender aspectos basilares, de gerenciamento e organização geral do ICASA em seus núcleos: equipe, fontes de renda, parcerias e constituição.

QUADRO 1: Informações relevantes sobre o funcionamento geral do Instituto Curupira, com informações sintetizadas a partir do site oficial. Fonte: (CURUPIRA, 2017)

\begin{tabular}{|l|l|}
\hline $\begin{array}{l}\text { Informações relevantes } \\
\text { sobre a ONG }\end{array}$ & Descrição \\
\hline Equipe & $\begin{array}{l}9 \text { diretores e 26 voluntários. Não há funcionários } \\
\text { remunerados na ONG. A instituição considera todos os } \\
\text { diretores como membros com igual potencialidade de } \\
\text { opinião e pró atividade. }\end{array}$ \\
\hline Fontes de renda da ONG & $\begin{array}{l}\text { Apoio de empresas, ações artísticas, cursos e vivências } \\
\text { científicas. A instiuição raramente consegue recursos de } \\
\text { editais e um favorecimento para sua manutenção é a sua } \\
\text { sede estar numa sala da Casa de Cultura de Barbacena, } \\
\text { desde 2015, com termo de uso cedido pela Prefeitura. }\end{array}$ \\
\hline & Orgãos governamentais, escolas, universidades, outras \\
\hline
\end{tabular}

ENCICLOPÉDIA BIOSFERA, Centro Científico Conhecer - Goiânia, v.17 n.32; p. 312020 


\begin{tabular}{|l|l|}
\hline Parcerias & $\begin{array}{l}\text { instituições não governamentais. Empresas tambem } \\
\text { apoiam mesmo com outros capitais, que não sejam } \\
\text { financeiros. }\end{array}$ \\
\hline Constituição & Estatuto e ata de fundação. \\
\hline
\end{tabular}

Importante destacar que o site da instituição tem sido atualizado desde 2017. Em relação à equipe, destacou-se o fato de não haver funcionários remunerados, sendo, então, uma Organização Não Governamental baseada totalmente em voluntariado. A fonte de recursos provém do apoio de empresas, cursos e vivências que a instituição oferece. Trata-se de uma entidade devidade regularizada, contando com Estatuto e ata de fundação.

\section{Uma análise dos projetos e ações educacionais do Instituto Curupira (ICASA)}

A compreensão de educação do ICASA não está vinculada à tradicional e popular definição, na qual processos educativos são geralmente baseados e restritos às salas de aula. Dois termos chave são constantemente destacados pelos manifestos Curupiras: Escola Aberta e Educação Ambiental Sensível (CURUPIRA, 2017) e, por isso, foi preciso perceber melhor o que significam dentro dos pressupostos político pedagógicos e ideológicos da instituição. As informações a serem utilizadas por esse estudo (via acesso ao site e mídias sociais da ONG e também jornais e outras fontes), pretendem possibilitar a percepção do impacto das ações da instituição na sociedade e orientou-se por dois critérios: (1) projetos ou ações, que tivessem sido realizadas nos últimos cinco anos (na discussão, focou-se mais especificamente em ações que tenham sido estabelecidas em Barbacena, $\mathrm{MG}$ ); (2) projetos ou ações que foram veiculados em mais de dois jornais, dispositivos de mídia externos à ONG. A coleta de informações recentes sobre a instituição, a partir das fontes já descritas, permitiu a construção do Quadro 2, que foi elaborada a partir de pressupostos de Bardin (2010), no sentido de escolher e hierarquizar os dados coletados:

QUADRO 2: Relação de projetos e ações do Instituto Curupira nos seus quatro núcleos. Dados obtidos a partir do site e mídias da instituição.

\begin{tabular}{|c|l|}
\hline Núcleos & Projetos executados \\
\hline Núcleo de Barbacena/MG & $\begin{array}{l}\text { 1 - Eventos culturais, artísticos e urbanos: } \\
\text { - Festival Nacional de Teatro }(2015,2016,2017) ; \\
\text { - Festival de Música Popular Livre (produzido anualmente) } \\
\text { - Produção cultural: shows e espetáculos teatrais } \\
\text { eventuais; } \\
\text { 2-Projetos e Núcleos de Pesquisa: } \\
\text { - Sophia: Núcleo de Pesquisa em Ecologia Holística; } \\
\text { - Capacitações em Ciências da Natureza e biologia da } \\
\text { conservação; } \\
\text { - Projeto Laboratório Vivo (desenvolvido em escolas } \\
\text { públicas de ensino fundamental e médio); } \\
\text { - Projeto "Árvore Literária", desenvolvido na praça principal } \\
\text { da cidade; }\end{array}$ \\
\hline
\end{tabular}




\begin{tabular}{|l|l|}
\hline & $\begin{array}{l}\text { - Projeto Afeto Urbano; } \\
\text { - NET (Núcleo de Estudos em Teatro); } \\
\text { - NEM (Núcleo de Estudos em Música) } \\
\text { - Banda Mangaia, criada em 2013 e em atuação } \\
\text { atualmente, busca a sensibilização e construção de sentidos } \\
\text { ambientais por meio de músicas autorais. }\end{array}$ \\
\hline \multirow{2}{*}{ Núcleo Campinas /SP } & $\begin{array}{l}\text { - Educação ambiental em espaços urbanos; } \\
\text { - Educação ambiental em espaços alternativos; } \\
\text { - Educação ambiental em universidades. } \\
\text { - Manifestos livres; } \\
\text { - Campanhas educativas baseadas em ecologia urbana, } \\
\text { permacultura e sensiência animal. }\end{array}$ \\
\hline $\begin{array}{l}\text { Núcleo Estados Unidos } \\
\text { (EUA) }\end{array}$ & $\begin{array}{l}\text { Projeto desenvolvido na cidade de Woburn, } \\
\text { Massachusetts, intitulado: "Woburn - water resources and } \\
\text { ecological relations." }\end{array}$ \\
\hline
\end{tabular}

Os núcleos acima listados são coordenados pela sede principal da instituição, em Barbacena/MG (CURUPIRA, 2017). Os procedimentos de administração e operacionalidade do ICASA são potencializados por mídias digitais de fácil acesso, característica da sociedade atual, marcadamente em rede. De acordo com informações disponibilizadas no site oficial da instituição, todos os projetos são intencionalmente construídos a partir de processos transdisciplinares ${ }^{\dagger}$ (CURUPIRA, 2017). O acesso ao site e demais midias da ONG desmonstrou que as ações desenvolvidas pela instituição são livres de partidarismos e envolvem grande quantidade de voluntários. Notou-se, desde o princípio do estudo, que seus pressupostos educativos e motivadores se associam ao que importantes teóricos ressaltam, em defesa de uma educação comprometida, num contexto claramente marcado por uma dedicação e pela ampliação das dimensões culturais a partir de processos pedagógicos; uma perspectiva de educação popular e historicamente localizada, com vários protagonismos, que vão além de práticas hegemônicas de perpetuação de discursos sobre o que é educar (KOHAN, 2019). A partir das informações colhidas no site, ficou bem marcado o interesse da ONG em praticar um modelo de educação que seja diferente, alternativo, e que busque novos moldes de ensino e aprendizagem, como se vê nos cursos e ações de popularização da ciência e da cultura. A instituição compreende a educação

como um processo complexo, baseado em aspectos culturais e de fortalecimento de valores, costumes, afetos e estímulos (...). O Instituto Curupira também desenvolve processos educativos baseados no conhecimento científico, popular e cidadão, sempre enaltecendo a formação humana como uma formação não dissociada da natureza, do meio ambiente e dos princípios fundamentais da ecologia. Tudo isso sempre transdisciplinarmente associado às diversas ações da instituição. (CURUPIRA, 2017, s/p)

+ Não foi escopo deste estudo analisar presencialmente os projetos e ações da ONG. Para compreender melhor os processos transdisciplinares seria preciso outro tipo de pesquisa, na qual envolvesse os discursos dos agentes participantes dos processos, membros e público atingido. Por isso optou-se, neste estudo, apenas pelo acesso a fontes discursivas da própria ONG via site e mídias e, alteras, como jornais e portais.

ENCICLOPÉDIA BIOSFERA, Centro Científico Conhecer - Goiânia, v.17 n.32; p. 332020 
Tais prerrogativas educativas da ONG, amplas e direcionadas para aspectos culturais também podem ser observadas em mídias que falam sobre diversas ações da instituição. Nesta pesquisa, é importante entender como setores da sociedade externos e não ligados ao ICASA compreendem alguns de seus projetos. Segundo o jornal Barbacena Mais (2016, $s / p)$ :

O trabalho do Curupira em Barbacena tem tido destaque pela movimentação cultural que o instituto oferece à cidade. Com eventos significativos e independentes, como o Festival de Música Popular e o Festival Nacional de Teatro, tem possibilitado o acesso à cultura às mais diversas classes e orientações sociais, numa verdadeira abrangência democrática e acessível da arte.

Outro jornal da região, o Barbacena Online (2020, s/p) destacou a importância para o município de um dos eventos promovidos pelo Instituto:

O Instituto Curupira sempre trabalhou com a proposta de voluntariado. Atualmente, a ONG tem núcleos em outras cidades brasileiras e também nos EUA. O Festival de Música Popular Livre tem 7 anos de existência e já trouxe a Barbacena artistas de várias partes do país e, claro, da cidade e região. Sendo uma instituição sem fins lucrativos, a ajuda de pessoas sempre foi, e é, fundamental para que o festival e outras ações continuem ocorrendo em Barbacena.

Fortalecendo tais perspectivas de impacto social, cultural e ambiental da ONG, em nível estadual, o Governo de Minas Gerais, a partir do Portal Mineiro de Teatro, dispõe em seu site:

Em 2012 firmou-se como Instituto, em formato de Escola alternativa, objetivando trabalhar a sensibilização ecológica e ambiental através da arte e da cultura. Em 8 anos de atuação já realizou cerca de 400 apresentações artísticas em várias cidades e regiões de Minas Gerais,contando atualmente com trabalhos teatrais de vários grupos e também de uma banda teatral/musical, chamada Mangaia. Um dos focos atuais teatrais da instituição é o teatro performático. O Curupira também possui núcleos em Massachusetts (EUA), Campinas (SP), e Norte de Minas (MINASGOV, 2017, s/p).

Essas informações colhidas junto a fontes externas ao Instituto Curupira, relativas ao modo como a ONG trabalha e constrói suas ações e projetos educativos, favorece notar/pensar a sustentabilidade como um aspecto necessariamente cultural, pois requer a mudança de hábitos, comportamentos e estruturas sociais historicamente construídas. Aspectos como o questionar de modelos tradicionais de educação, com proposição de linguagens alternativas, a partir de estratégias diferentes, sendo a arte, um exemplo, como "Escola Aberta" (CURUPIRA, 2017, s/p), ou processos de divulgação de ciência, em campo, com cursos que ocorrem na prática, no meio do contexto urbano ou em Unidades de Conservação, favorecem 0 entendimento de que novos processos inter $e$ transdisplinares podem ser mediados e propostos, em diferentes setores da sociedade.

A transdisciplinaridade, como bem mostra D'ambrosio (2011) é bem complicada de ser definida e praticada, mas, em geral, é possível, pelo menos, aproximar esse conceito das discussões geradas pela ONG. Brocchi (2008) defende 
que é preciso que se compreenda e elabore o âmbito cultural da sustentabilidade. Se ela envolve hábitos, costumes e valores, então, necessariamente está no âmbito cultural, daquilo que é construído em contextos e práticas sociais. Dessa forma, a educação é uma das mais importantes aliadas para as perspectivas de sustentabilidade (GADOTTI, 2016), tão amplamente buscadas e discutidas na contemporaneidade. Na página inicial do site há informações que evidenciam que a sustentabilidade da própria instituição é muito baseada na gestão de pessoas e nas parcerias tidas desde com escolas, universidades, outras ONGs e até empresários (CURUPIRA, 2017).

Compreende-se que educar não é apenas o processo escolarizante, mas, também, e talvez sobretudo, o ato de gerar estímulos e processos de mudança de percepção, de comportamento (KOHAN, 2019), de visão de mundo. Considerando esses pressupostos e interpretando as ações da ONG, dispostas no Quadro 2, como os Festivais de Música e Teatro, e as atividades artísticas performáticas, que são realizadas criticamente acerca de aspectos ambientais, por exemplo, é possível notar o uso de estratégias diferentes de educação. Essas manifestações favorecem outras maneiras de interpretação e entendimento de um assunto ou de um tema, pelas pessoas que assistem/interagem com a proposta. A Figura 1, permite notar a linguagem usada pela instituição, em seus processos educativos via arte. $\mathrm{Na}$ imagem, uma performance artística é feita no centro de Barbacena/MG, no local onde 22 árvores foram cortadas, em 2016.

FIGURA 1: Performance art em manifesto contra o corte de árvores da região central de Barbacena/MG

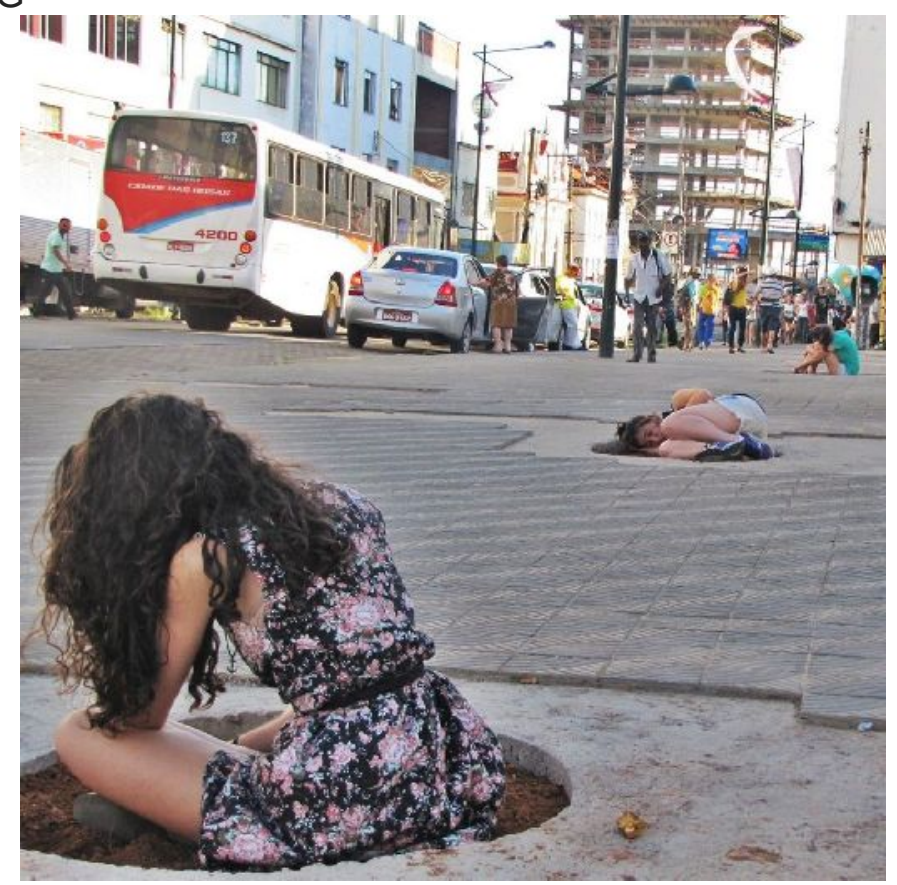

Fonte: CURUPIRA, (2017, s/p.)

As perspectivas urbanas, de geração de afetos (CAPRA, 2005), sentidos ambientais (OLIVEIRA et al., 2016) notadas nessa ação do ICASA favorecem refletir sobre a instância cultural da sustentabilidade. As pessoas, ao notarem os artistas, assentados nos buracos vazios, onde antes haviam árvores, a maioria nativas, certamente se questionaram, pensaram e refletiram sobre o que houve ali. É uma ação claramente incentivadora de interpretações ambientais, principalmente quando associada à compreensão que Cesnik e Beltrame (2005), oferecem acerca de 
cultura, ao a caracterizarem como elemento que confere unidade, sentido e reconhecimento a uma sociedade.

No caso do manifesto crítico acerca do corte das árvores, há a correlação direta entre símbolos culturais, já que as árvores que estavam na praça central do município há décadas faziam parte da identidade cultural das pessoas, conferindo unidade, sentido e reconhecimento, dinâmicas elementares para quaisquer processos de interpretação identitária de um povo.

A unidade remete aos processos de identificação e representação do mundo, de construção de identidades (CASTELLS, 1999), por sua vez geradora de sentidos baseados em contextos que permitem a existência de diversos níveis de conhecimento e reconhecimento. Não há, portanto, possibilidade de reflexão sobre a cultura, sem antes percebê-la como resultado dessas representações e identificações da humanidade (MORIN, 2007), e suas sociedades, nos mais diversos ambientes. Diante disso, como mostra Brocchi (2008), mudanças culturais são a base para qualquer processo de mudança de modos de atuação humana na Terra, seja com relação a fatores socias, seja com relação a aspectos ambientais e econômicos. Esta seria, segundo o teórico, uma dimensão cultural da sustentabilidade.

É nesse contexto que essa pesquisa foi motivada e construída. A compreensão essencial do desenvolvimento sustentável implica em desafio cultural, pois relaciona-se à mudança de perfis éticos e estéticos do modo como a humanidade compreende a si mesma e ao mundo que a cerca (GADOTTI, 2016). A sustentabilidade é, portanto um discurso cultural, fortemente alicerçado no que cria estímulos e afeta; no que orienta a construção de valores e formas; no que estabelece relação entre a estética, como atuação no mundo (e aqui a discussão da arte), as urbanidades e tudo o que contrabalança os preceitos e interesses da economia, da ecologia e das sociedades (CAPRA, 2005).

Outro aspecto relevante a ser considerado é a associação entre transdisciplinaridade e sustentabilidade, que evidencia uma abordagem de cultura mais voltada para o nível de interrelacionamento das sociedades globais (CASTELLS, 1999). Para os fatores que, baseados nos modelos contemporâneos, fortalecem a discussão sobre os modos como os sistemas culturais marcam e constroem as relações e práticas sociais, orientadas como processos de significação e construção identitária. Logo, compreender os processos transdisciplinares do Curupira significa, portanto, uma rica oportunidade de alçar melhores percepções sobre como é possível construir propostas alternativas de mudança cultural, de forma descentralizada e não governamental.

\section{Refletindo sobre transdisciplinaridade: uma resposta à sustentabilidade}

Assim como a definição de cultura, a transdisciplinaridade possui uma série de atribuições teóricas, algumas das quais, segundo muitos estudiosos, de difícil aplicação prática. $O$ termo frequentemente tem sido interpretado por alguns segmentos da sociedade mais pelo olhar da desconfiança e utopia (D’AMBROSIO, 2011), que pelo olhar da aplicabilidade e sistematização.

Amiúde, a dissociação da humanidade da natureza é percebida em várias instâncias da sociedade e está relacionada ao modo como o homem significou e agiu sobre o mundo, e sobre sua própria essência como espécie, nos últimos séculos. Desconstruir esses valores estruturais negativos ao equilíbrio ambiental global requer ações intensivas, culturais e educacionais, que busquem entender 0 ser humano como parte da natureza e, claro, a natureza também como parte da 
ciência, da cultura e da sociedade. Por isso a sustentabilidade passa, necessariamente, por uma mudança de paradigmas (BROCCHI, 2008).

Considerando esses aspectos, desponta a relevância da transdisciplinaridade como valor cultural fundamental para um futuro sustentável. D’ambrósio (2011), oferece rica discussão acerca dos elementos que caracterizam um processo transdisciplinar, mas que, segundo ele, somente são perceptíveis e aplicáveis quando distanciados das características tradicionais da construção e transmissão do conhecimento e valores. Algo muito próximo do que defende, discursivamente, o Instituto Curupira, ao compreender a educação como uma amplitude de complexos imbricados, marcados por processos formativos voltados para diversos públicos, desde crianças e adolescentes, até adultos, sobretudo por meio de eventos, culturais e ambientais (CURUPIRA, 2017).

Nota-se como a discussão cultural encorpa também o debate sobre o que é transdisciplinaridade: uma vez partindo de pressupostos de valores, modelos e significação, e suas possibilidades de mudança, necessariamente fala-se de cultura. Exatamente por isso, D’ambrósio (2011, p.12), declara que o princípio essencial da transdisciplinaridade é o reconhecimento das dimensões "sensorial + mística + emocional + intuitiva + racional do conhecimento e a integridade mente + corpo + cosmos", algo que oferece incondicional e profundo suporte a uma percepção ética de maior respeito, solidariedade e cooperação. Ainda segundo o teórico, a transdisciplinaridade contribui para a tomada de consciência da alteridade, da construção inerente que a vivência com o outro, com a dinâmica social provoca na vida de todo cidadão. Trata-se de uma descoberta e prática para a consciência, compreendendo a humanidade como muito além de um fator biológico, mas, também transcendental e espiritual: a transculturalidade (D'AMBROSIO, 2011).

Entra-se, inevitavelmente, nas discussões sobre educação. $O$ encontro do conhecimento e da consciência, dos complexos de explicação e convivência da realidade, é possibilitado em níveis educacionais, mas não apenas os formais. A educação, em seu perfil libertador e formador, que conduz à ética e à moral, não pode ser compreendida somente como um processo de formalização do conhecimento. É, acima de tudo, uma ação de condução à antropoética, baseada na externalização da condição humana a partir da tríade:indivíduo, sociedade e espécie (MORIN, 2007), na elaboração de uma cidadania terrestre.

Cultura e educação, portanto, são pontos chave de estudo, e sua associação em prol de uma compreensão diferente dos modelos estruturantes do conhecimento e da sociedade se dá no rol múltiplo da transdisciplinaridade. É possível entender algumas das ações e projetos do Instituto Curupira como inter e transdisciplinares, ao compreender-se a transdisciplinaridade como uma resposta à sustentabilidade (D’AMBROSIO, 2011). Tendo como base as informações colhidas no site da ONG e o que ja foi discutido, a partir de jornais externos, os aspectos abaixo figuram como um possível indicativo de ação inter e/ou transdisciplinar da instituição:

1 - mútua colaboração de pessoas com sentimentos e propósitos de mundo semelhantes; 2 - organização de conhecimentos coletivos, (...) compreendendo a educação pelo viés da interpretação e representação ética e estética das realidades; 3- práticas afetivas baseadas na percepção holística de pontos chaves de construção de saberes e sentidos ambientais. A associação destes pressupostos cerne, apoiam a elaboração de todos os atuais projetos do ICASA, em todos os seus pólos de atuação. (CURUPIRA, 2017, s/p)

Nota-se, a partir do que preconiza D'ambrosio (2011), que a 
transdisciplinaridade é percebida, pelo ICASA, não como uma metodologia fixa, mas sim como processos. Os três argumentos fundamentais da prática transdisciplinar do Instituto revelam a associação constante entre conhecimentos culturais subjetivos e coletivos, compreensões éticas e estéticas das realidades e visão holística, sistêmica dos modelos de projetos educativos e culturais a serem construídos. Tudo isso corrobora com a definição da transdisciplinaridade como resposta à sustentabilidade (D'AMBROSIO, 2011), pois ela permite a associação de saberes e percepções de mundo orientados para a mudança de comportamentos, situações e até práticas políticas, ambientais e econômicas historicamente construídas. Logo, é a potencial instigadora da associação dos fatores chave do tripé da sustentabilidade tradicional: ambiente, sociedade e economia (CAPRA, 2005).

Desde os festivais culturais, que contam com a presença de artistas de vários estados do Brasil, sempre em formato de "Escola Aberta" e "Educação Ambiental Sensível" (CURUPIRA, 2017, s/p), compreendendo a cultura como educação pró sentidos e afetos ambientais, até os projetos art, os propósitos de pesquisa científica e de educação ambiental mais popular, é perceptível a associação do três argumentos acima citados. Também é possível perceber nos planos de voluntariado do Instituto Curupira a essência que nutre e constrói a instituição e que, certamente, é a grande responsável por sua representatividade local, estadual e nacional.

De acordo com as informações colhidas no site e nas mídias da instituição, e também em noticias de jornais, dentre outros, acredita-se que Escola Aberta é o conceito que melhor abrange o modelo de proposta educacional do ICASA: uma escola alternativa sem limites e sem fronteiras, na qual diversas ações acontecem gerando afetos e estímulos; fortalecendo olhares sensíveis para a alteridade e para as ambientalidades. Sendo assim, a "Educação Ambiental Sensível" (CURUPIRA, 2017, s/p) desponta como um conjunto de saberes possíveis de serem construídos, adaptativos e geradores de valores ambientais.

\section{Educação Ambiental Sensível, cultura e transdisciplinaridade}

Ainda no começo do século XIX Karl Marx já apontava rumos que a humanidade, em seu modelo industrial, desenhava para o âmbito de suas relações com o ambiente, com a natureza e consigo mesma. Já naquele tempo, o teórico discutiu a maneira pela qual o modelo capitalista interferia na forma como o homem compreendia-se subjetiva e coletivamente (DELLA FONTE, 2019) como se percebia no ambiente e as maneiras como representava a natureza.

Marx previu uma crise socioeconômica, segundo ele, um dos maiores responsáveis pela injustiça e iniquidade presentes nas sociedades de então. Um caos alicerçado em diversas ideias construídas discursivamente, com objetivo de justificar a industrialização, o pré consumismo e a apropriação de recursos naturais para a "existência" humana. Ele rejeitava a concepção de que as formas de desenvolvimento da sociedade industrial eram inerentes à "essência humana" e que a questão era adaptar o modelo capitalista ao cotidiano. Esse panorama da ideia Marxista é importante, pois possibilita perceber que (1) a sociedade contemporânea, e seus perfis culturais, foi e ainda é paulatinamente construída, mas, como se nota, é calcada nos fortes princípios do capital, dos modelos cartesianos de percepção do mundo e de construção da realidade; (2) esses fatores, associados às inovações tecnológicas do último século, que potencializaram realidades culturais em trocas constantes, híbridas e não fixas, são elementos chave para a sociedade em rede (CASTELLS, 1999, p. 17)

Um mundo, com apropriações e resignificações culturais constantes, é o que 
se vislumbra na contemporaneidade. A fluidez das realidades, o relacionamento entre a humanidade e o ambiente, a natureza e as questões urbanas, resultou, para muitos estudiosos, numa espécie de desapropriação do senso comunitário. Castells (1999, p.78), no entanto, afirma que, apesar do desaparecimento aparente da noção de comunidade, primeiro em razão da urbanização e, depois, por causa suburbanização, é possível alçar novas concepções sobre a maneira como as pessoas significam-se coletivamente. Ainda que a globalização massifique, sob o símbolo da unidade e prosperidade, a cultura mundial, identidades locais continuam a se fortalecer. Oferecem modelos de existência e processos adaptativos ricos, capazes de alavancar a construção da vida como algo compartilhado, como possibilidades de produção de novos significados. (CASTELLS, 1999).

Nesse âmbito, a questão da educação, relacionada diretamente à questão cultural, desponta. A produção de significados está arrolada diretamente a fatores culturais e representacionais, elaborados no conjunto das relações sociais, ambientais, de natureza comum, que associam as pessoas, suas compreensões do mundo e da vida que têm. O sentimento de pertença, de importância numa realidade ambiental, por exemplo, não se baseia meramente na existência das pessoas, mas também e, sobretudo, nas múltiplas identidades e valores que as associam e caracterizam como comunidades sociohistoricas, com características de ligação fortes, estabelecendo laços de identidade (CASTELLS, 1999)

As configurações tradicionais de instituições brasileiras e o modelo de educação formal encaixam-se numa padronização, que muito confere às instituições que se encontram nesse contexto uma estrutura que muitas vezes inibe a inserção de projetos, propostas alternativas de solução e discussão de problemáticas. A partir dos pressupostos arrolados acima, por Castells (1999), de certa forma é possível compreender o Instituto Curupira como uma "comuna cultural" (CASTELLS, 1999, p.85), construída a partir da matéria prima fornecida pela história, geografia, língua e ambiente, voltadas para a construção de saberes e valores alternativos ao que hegemonicamente é instituído pelas estruturas formais de poder.

Lançando olhar para as questões educativas, Kohan (2019) ao discorrer sobre Paulo Freire e seu conceito de educação libertadora, contribui bastante com esta pesquisa. Os processos mais sensíveis de educação devem conduzir à emancipação dos indivíduos num complexo de reações e projetos determinados por fatores históricos (CASTELLS, 1999), que se associam à dimensão de valores estéticos e éticos algo perceptível nas ações do ICASA.Justamente aqui, na associação entre o que é estético e o que é ético, que a "Educação Ambiental Sensível" (CURUPIRA, 2017, s/p) certamente se constrói: uma educação da atenção, em contrapartida à mera transmissão e representação, afinal, o conhecimento não consiste em proposições sobre o mundo, mas sim do engajamento sensorial com 0 ambiente. Esse engajamento sensorial pode ser notado em diversas ações, conforme as Figuras 2 e 3. 
FIGURA 2: Fotografia coletada no instagram do ICASA: projeto "Afeto Urbano".

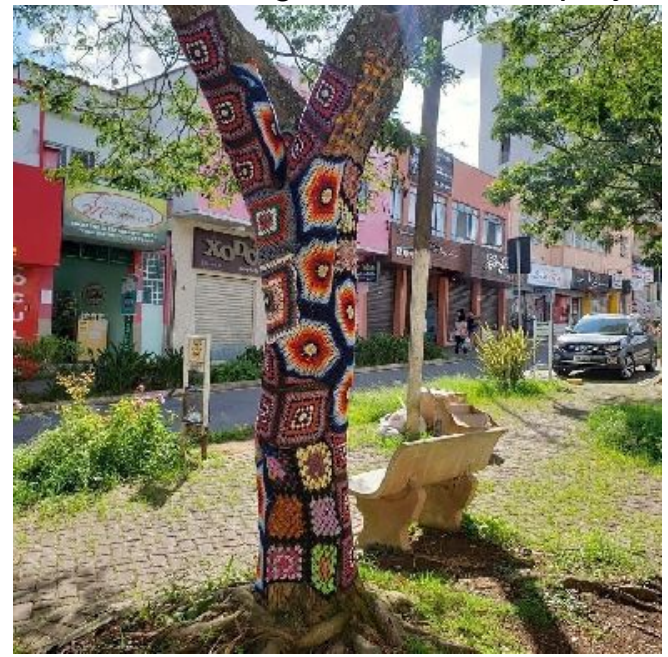

Fonte: Instagram Instituto Curupira (2020).

FIGURA 3: Fotografia coletada no Facebook do Instituto Curupira: Companhia Negra de Teatro, no Festival Nacional de Teatro de Barbacena, da ONG, em 2016.

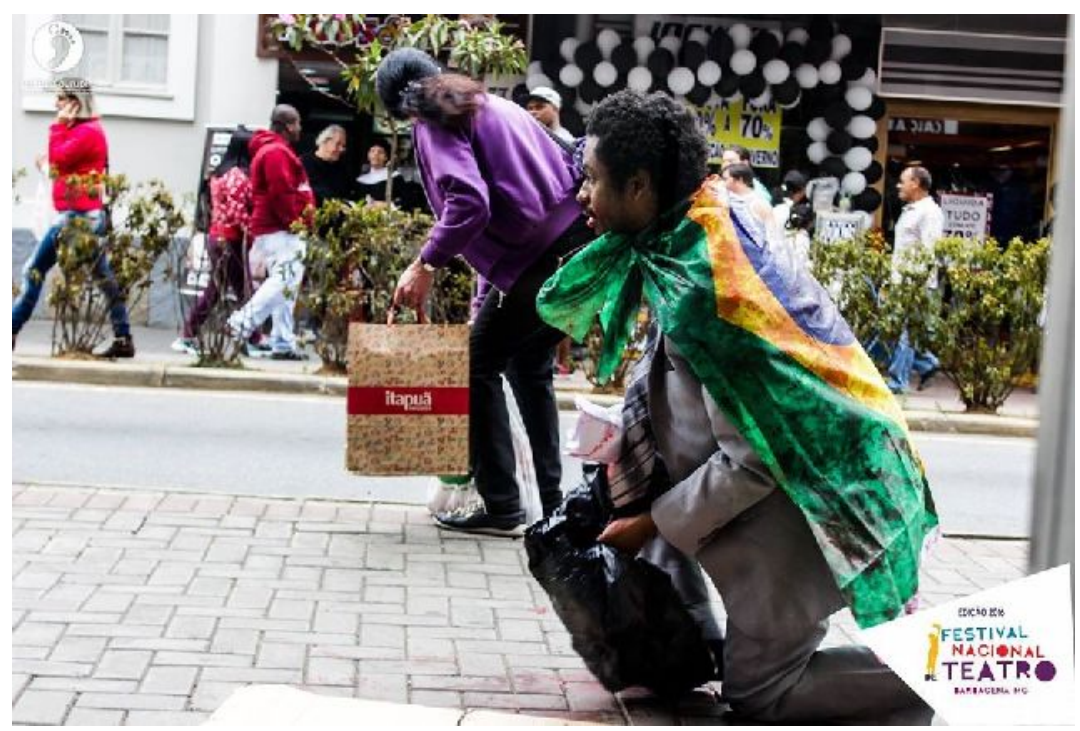

Fonte: Facebook Instituto Curupira, (2020).

A “Educação Ambiental Sensível” (CURUPIRA, 2017, s/p) desponta como importante instrumento de ação para todas as iniciativas educacionais do ICASA, por seu caráter politizado, problematizador e questionador (conforme nota-se nos "incômodos" gerados num espetáculo teatral realizado no meio das ruas, numa dinâmica bem diferente do que convencionalmente é trazido). Pode-se, então, relacionar esse caráter questionador a uma perspectiva contra hegemônica, interdisplinar e, em contrapartida, a uma educação ambiental que é mais conservadora (GUIMARÃES, 2004).

Por seus perfis de construção crítica da realidade, os projetos desenvolvidos pela instituição possuem relação direta com perspectivas gerais da educação ambiental, sobretudo pela tentativa de motivar o pensamento crítico, inclusive de forma não formal, alçando processos de transformação e significação, contribuindo para a formação de cidadãos críticos e sujeitos ambientais ativos em suas realidades (BRASIL, 2016). Tais perspectivas permitem pensar os indivíduos muito além de suas instâncias subjetivas. Permite compreendê-los como construtores de 
suas vidas, de seus projetos existenciais. Possibilita, ainda, refletir sobre o que afeta e estimula; o que pode incentivar a mudança de comportamento frente a problemas sociais e ambientais. A cultura, e seu caráter fluído, evocam a estética como um processo de imersão no mundo (CASTELLS, 1999). Não se restringe à dimensão do belo. É experiência sensível, socialmente construída e significada. É um instrumento de empoderamento do indivíduo para o envolvimento com as realidades, para a participação e interação social e ambiental; sobretudo, para torná-lo importante e participante de uma construção cultural que o faça sentir-se parte de seu mundo.

A transdisciplinaridade, a percepção das complexidades, a educação e a construção de sentidos e valores ambientais, como se vê, estão conectadas pela rede fornecida pela cultura (D'AMBROSIO, 2011). Logo, novas formas de significação das realidades, e de atuação sobre elas, partem necessariamente de diferentes processos de aprendizagem, de práticas cidadãs e políticas e, acima de tudo, de inovadoras formas de posicionamento crítico sobre os conhecimentos que são oferecidos e definidos pelas bandeiras da hegemonia, do capital e do estado, que evidentemente dificilmente possibilitarão uma real construção da sustentabilidade. O próprio hábito de questionar é um ato de libertação (KOHAN, 2019). Exatamente por isso foi elementar, nesse artigo, a análise da construção de sentidos e saberes ambientais nos projetos do ICASA, compreendendo esses processos como cernes de emancipação e construção de culturas de sustentabilidade, afetivas e estimulantes

O Instituto Curupira (ICASA) apresenta perspectivas interessantes de desenvolvimento de uma educação voltada para a sustentabilidade, com significativos incentivos ao questionamento e reflexão; projetos educacionais de elaboração poética da realidade num viés crítico ambiental, possibilitados por procedimentos diferentes de construção de saberes, diálogos e de sentidos (MORIN, 2007). Embora o acesso às informações via site e outras mídias da ONG, e também fontes externas, como os jornais mencionados, não sejam capazes de revelar totalmente a estrutura e o funcionamento geral da instituição, é possível depreender que as ações da entidade destacadas neste estudo questionam os arquétipos padronizados e difundidos pela sociedade, inclusive os paradigmas opostos da relação homem natureza, que tanto dissociam e não integram os saberes e as trocas, desestimulando, ou não incentivando, qualquer proposta de transdisciplinaridade e sustentabilidade.

\section{CONCLUSÃO}

Percebe-se, em conclusão, que o ICASA possui interessantes modelos de construção de valores e sentidos ambientais, fortemente baseados em princípios culturais, tendo como suporte ideológico a perspectiva de que a sustentabilidade é uma construção cultural e transdisciplinar. A partir desses pressupostos, sobretudo baseados em perspectivas de mudança cultural, o modelo de Escola Aberta de seus processos educativos, que são elaborados em desígnios de Educação Ambiental Sensível, variam desde a produção de eventos culturais, como o Festival de Música Popular Livre e Festival Nacional de Teatro, até projetos de pesquisa, como o Sophia (Núcleo de Pesquisa em Ecologia Holística), o Afeto Urbano e ações várias de educação ambiental, como os diversos propósitos desenvolvidos em escolas e praças públicas, e ambientes sociais múltiplos, todos sempre com anseios inter e transdisciplinares. Nesse contexto, tão rico de atuação livre e independente, o Instituto Curupira pode ser considerado uma trincheira de resistência contemporânea exatamente por propor novas linguagens de percepção do mundo, 
sempre em formação, transformação e resiliência.

Em suma, pode-se afirmar que o Instituto Curupira é um incentivo a novos olhares sobre às realidades urbanas e ambientais, à educação e aos processos culturais humanos. Também é um interessante foco de estudo sobre o desenvolvimento de práticas de transdisciplinaridade, compreendo-a como fundamental fator de mudança e construção de perfis sustentáveis de atuação antrópica no planeta.

\section{REFERÊNCIAS}

ANTUNES, A.; ABREU, J.; PADILHA, P. R. Artigos e projetos de intervenção produzidos durante o curso: A escola dos meus sonhos ministrado pelo professor Moacir Gadotti. São Paulo : Instituto Paulo Freire, 2018.

BARBACENAMAIS. Gente que faz: Instituto Curupira inaugura nova sede em Barbacena/MG (2016). Disponivel em <https://bit.ly/2AJZP8f> Acesso: 12 de abril de 2020.

BARBACENAONLINE. Instituto Curupira - Festival de Música Popular Livre de 2020. Disponível em <https://bit.ly/37bNRQY>. Acesso: 05 de maio de 2020.

BARDIN, L. Análise de conteúdo. São Paulo: Edições 70, 2010.

BROCCHI, D.The Cultural Dimension of Sustainability. In: S. Kagan, V.Kirchberg (Eds.), Sustainability: a new frontier for the arts and cultures, VASVerlagfür Akademische Schriften, Frankfurt am Main, 2008.

BRASIL, Ministério do Meio Ambiente.; Princípios da Educação para Sociedades Sustentáveis e Responsabilidade Global. Congresso Nacional, Brasília, 2016.

CAPRA, F. Educação. Meio ambiente no século 21: 21 especialistas falam da questão ambiental nas suas áreas de conhecimento. RJ, Sextante, 2005.

CASTELLS, M. A era da informação: economia, sociedade e cultura, vol. II. O poder da identidade. SP: Paz e Terra, 1999.

CESNIK, F; BELTRAME, P. A. Globalização da Cultura. São Paulo: Manole, 2005.

CURUPIRA, I. - Instituto Curupira: Escola alternativa de educação ambiental e ecocultural. Disponível em <institutocurupirae.wixsite.com/institutocurupira (2017)> Acesso em: 01 de abril de 2020. Barbacena, MG, 2020.

CURUPIRA, I. Album de fotos/ Instituto Curupira, on Facebook. Disponível em<https://bit.ly/2ANrHYW>. Acesso: 02 de maio de 2020.

CURUPIRA, I. Album de fotos/ Instituto Curupira, on Instagram. Disponível em<https://bit.ly/3dD6aRj>. Acesso: 02 de maio de 2020.

D’AMBROSIO, U. Transdisciplinaridade. Editora Palas Athena. 2011.

DELLA FONTE, S.S. Marx e a literatura em O capital (2019). Disponível em $<$ https://bit.ly/2BBadPQ>. Acesso: 02 de maio de 2020. 
GADOTTI, M. Pedagogia do oprimido - leitura de seus leitores e intérpretes. São Paulo: Instituto Paulo Freire, 2016.

GUIMARÃES, V. S. Formação e professores: Saberes, identidade e profissão. Campinas: Papiros, 2004.

IBGE. As Fundações Privadas e Associações sem Fins Lucrativos no Brasil FASFIL. Instituto Brasileiro de Geografia e Estatística, 2017. Disponível em: $<$ https://www.ibge.gov.br/estatisticas/economicas/outras-estatisticaseconomicas/9023-as-fundacoes-privadas-e-associacoes-sem-fins-lucrativos-nobrasil.html?=\&t=o-que-e> Acesso em: 12 de maio de 2020.

KOHAN, W. O. Paulo Freire e o valor da igualdade em educação. Educ. Pesqui., v. 45, e201600, 2019. ISSN: 1517-9702 . DOI: 10.1590/s1678-4634201945201600.

MINASGOV. Portal do Teatro Mineiro: Instituto Curupira (2017). Disponível em<http://www.teatromineiro.mg.gov.br/component/k2/instituto-curupira>. Acesso: 23

MORIN, E. Os sete saberes necessários à educação do futuro. Editora: Cortez, Unesco, 2007.

OLIVEIRA, H. T. O; FIGUEIREDO, A. N.; TULLIO, A. D.; MARTINS, C.; THIEMANN, F. T., et al. Educação Ambiental para conservação da Biodiversidade/animais topo de cadeia. Ed. Diagrama, São Carlos, SP. 2016.

ONU (ORGANIZAÇÃO DAS NAÇÕES UNIDAS). Transformando Nosso Mundo: A Agenda 2030 para o Desenvolvimento Sustentável, 2015. Disponível em < https://nacoesunidas.org/pos2015/agenda2030/>. Acesso em 12 de maio de 2020. 